\title{
Methodological improvement of testing of selected parameters for fire resistance of wood and wood-based materials using the MFT
}

\author{
Wojciech L. Grześkowiak ${ }^{1}$ Krzysztof Moliński \\ ${ }^{1}$ Institute of Chemical Wood Technology, Poznan University of Life Sciences, 38/42 Wojska \\ Polskiego, 60-637 Poznan, Poland, wojciech.grzeskowiak@up.poznan.pl \\ ${ }^{2}$ Department of Mathematical and Statistical Methods, Poznan University of Life Sciences, \\ 28 Wojska Polskiego, 60-637 Poznan, Poland, krzysztof.molinski@up.poznan.pl
}

\section{SUMMARY}

\begin{abstract}
There are many methods used to determine the reaction to fire of wood and wood-based materials, ranging from full-scale to small-scale testing. One of the small-scale techniques is the use of the Mini Fire Tube (MFT). The aim of this work is to optimize the assessment of fireproofing preparations for wood and wood-based materials using the MFT. In addition, an evaluation was made of the effectiveness of the protection in relation to the maximum temperature of the control sample. An attempt at optimization was made using the example of pine wood and selected flame retardants. Based on the results of control tests, the critical point (the time at which the average sample temperature reached its maximum value) was calculated (Grześkowiak and Moliński 2019). The effectiveness of the protection at the critical point was determined. Efficiencies were calculated for all time parameters to determine the optimal test time. A formula was proposed for the duration of tests for protected samples, taking as a reference the maximum temperature of the control series. The tests showed that it is possible to shorten the time for testing of the effectiveness of flame retardants based on the time taken to obtain maximum temperature for control samples.
\end{abstract}

Key words: Mini Fire Tube (MFT), flame retardants, critical point, optimization

\section{Introduction}

A basic feature that distinguishes wood from materials such as concrete and steel is its flammability. It has been known for years that unprotected steel, concrete and stone are much less resistant to high temperatures than wood. The carbon layer formed during a fire protects the interior of wooden elements such as beams, to a degree that allows them to maintain their load capacity for a long time (Goldstein 1973, Park et al. 2012, Marney et al. 
2005, Chapple and Anandjiwala 2010). Despite having many advantages, such as strength, low thermal conductivity and ease of processing, wood also has some disadvantages. Chief among these are susceptibility to biotic agents and fire (Goldstein 1973). The fire resistance of wooden structures and their elements is directly dependent on the type of wood and its physical properties (Le Van 1989). To give wood greater durability during exposure to fire, it should be protected with fireproofing preparations. These preparations can reduce the flammability of wood, although they cannot produce a non-combustible material (Oberley 1991). Research on flame retardants has a long history, and their importance is constantly increasing. The introduction of flame retardants for production and application in practice has enabled a reduction in human and material losses. The quality and effectiveness of flame retardants are increasingly important for safety, applications, economy and environmental protection (White and Dietenberger 2001, Fanfarova et al. 2016).

The development of wood-based construction entails many problems, such as the availability of appropriate raw materials, ecological concerns, and fire safety problems associated with the use of wood materials. In today's construction industry, the use of wood and wood-based materials is very extensive. They are used for the production of frame structures of buildings, finishing and decorative elements, and furniture. OSB has found wide application in frame construction, for example as webs in load-bearing beams of roof constructions as well as walls and ceilings. In addition to OSB boards, which are basic in construction, fiberboards, chipboard and plywood, or CLT and LVL materials are increasingly being used (Winandy et al. 1988).

The behavior of wood and wood-based materials in burning processes means that it is necessary to obtain experimental data to determine the usefulness of a given material for various applications. The use of wood and wood-based materials in buildings in places exposed to high temperatures can lead to the ignition of the material and, consequently, to a fire. The susceptibility of wood and wood-based materials to the burning process and the possibility of self-ignition are determined by such factors as dimensions, humidity and density of the raw material, speed of air flow, geometry of the combustion system, thermal conductivity and fire protection, as well as the time of heat exposure (Sulaiha et al. 2019, Grześkowiak et al. 2011). 
The basic characteristic determining the fire properties of building materials or structures is their reaction to fire. This type of research is helpful in assessing the contribution of materials to the initial stage of fire development. Relevant properties include susceptibility to inflammation, released energy, fire spread on the surface of the material, and the production of smoke and burning particles. Research on reaction to fire tends to use methods on a smaller scale than the fire resistance tests described in the EN13501-2 standard, focused on the size and structure of building systems (Zeinali et al. 2018). In the case of tests for reaction to fire, important factors include the appropriate selection of samples, their dimensions (depending on the scale of the tests), the density of the material, the function to be performed by the tested material, and its homogeneity (Lowden and Hull 2013).

Depending on the type of material, its intended use and whether it is fire-protected, different methods are applied to model the behavior of a material in a real fire. In the case of wood and wood-based panels, an important role is played by ignition time, flame spread rate, carbonization rate, HRR, FIGRA, and mass loss and temperature as a function of time. When a fire retardant material is considered, the key role is played by such features as the amount of the preparation, its distribution in the material and methods of protection (Zeinali et al. 2018). Studies on the behavior of materials under the influence of flame and heat radiation on a small laboratory scale are mainly based on measurements of mass loss, temperature, carbonization rate and HRR. They are carried out with standard methods such as the cone calorimeter, as well as non-standard ones (Zeinali et al. 2018).

Most flammability tests of building materials are designed to provide information on reaction to fire. They take into account the need to use appropriate methods implemented by governmental and scientific institutions. Many different flammability testing methods have been developed to reflect many fire scenarios, with samples of various dimensions and orientations being subjected to fire. Depending on the fire scenario applied, flammability test methods can be classified as small-, medium- and full-scale. The basic properties of materials can be tested by small-scale methods. However, comprehensive testing of the properties or flammability of materials from the moment of ignition to the phase of a fully developed fire requires the use of full-scale methods. This results in a significant increase in the costs of tests, quantities of materials and test duration. On the other hand, the results 
of tests on a medium or small scale do not always correspond to the data obtained from fullscale tests (Chung et al. 2014).

There are many methods used to determine the reaction to fire of wood and wood-based materials, ranging from full-scale to small-scale testing. One of the medium-scale techniques used to determine the reaction to fire of fireproofed wood is the Truax-Harrison method, described in the ASTM E69-2 standard (www.astm.org 2002). It is a relatively cheap method and does not require specialized software. The tests are carried out on samples placed vertically in a pipe. The method uses 1000 x 20 x $10 \mathrm{~mm}$ samples exposed to a $250 \mathrm{~mm}$ high flame for 4 minutes. The scale of the test is not suited to the investigation of protected structural elements, but it is a method useful for research and development purposes as well as quality control of fire protection.

Due to the relatively large dimensions of the samples, attempts have been made to modify this method, including reducing the size of the samples and shortening the test time, while maintaining appropriate correlations with the original method. One of the modifications of the ASTM E69-2 method was an attempt to reduce the dimensions of the apparatus, and thus the dimensions of the samples, without reducing the flame time. The mass of samples (up to $15 \mathrm{~g}$ ) was modified, as well as the distance of the flame front acting on the sample (up to $6 \mathrm{~cm}$ ). In the original method, the flame front was in contact with the front of the suspended sample (Fouladi et al. 2015).

Another proposed modification of the ASTM E69-2 method is the use of the Mini Fire Tube (MFT) method, developed at the PULS Institute of Wood Chemical Technology and described below.

The aim of this work is to optimize the assessment of fireproofing preparations for wood and wood-based materials, fire characteristics and fire resistance of materials using the MFT. In addition, based on the temperature characteristics of the control sample, an evaluation was made of the effectiveness of protection in relation to the maximum temperature of the control sample. An attempt at optimization was carried out using the example of pine wood and selected flame retardant preparations. 


\section{Materials and methodology}

\subsection{Materials}

The research used two variants of a laboratory-made model preparation (A and B) being the subject of a patent, and a commercial preparation (C) whose main components were ammonium phosphorus compounds. The preparations were tested at the working concentration of the solution (10\%). The control samples (K) were unprotected.

Pine sapwood (Pinus sylvestris L.) samples were used. The samples taken were free of defects, with a humidity of $8 \pm 0.5 \%$ and dimensions of $5 \times 10 \times 100 \mathrm{~mm}$. The test samples were treated in vacuum dryers using the full-cell vacuum method with a vacuum of $0.1 \mathrm{MPa}$ maintained for $20 \mathrm{~min}$, and kept in solutions for the next 2 hours under atmospheric pressure. After impregnation, the samples were air-conditioned for 14 days at a temperature of $23 \pm 2{ }^{\circ} \mathrm{C}$ and a humidity of $65 \pm 5 \%$, to obtain a wood moisture content of $8 \pm 2 \%$. Tested control samples had the same moisture content. The moisture content of the samples was determined by the drying-weighing method. For each test variant, 10 samples were used for the study.

\subsection{Flammability testing methodology}

The MFT (Mini Fire Tube) method is a modified version of the ASTM E69-2 method. It is more accurate and allows for more repetitions. The method is based on measurements of mass loss and exhaust gas temperature at the pipe outlet. The test stand consists of a $2 \times 2$ $\mathrm{cm}$ aluminum tube placed on a laboratory balance, a gas burner, and a thermocouple with a temperature range from -50 to $1200{ }^{\circ} \mathrm{C}$. The balance and thermocouple are connected to a computer that records changes in mass and temperature during the test. Then the burner is fed inside the pipe with a flame about $1 \mathrm{~cm}$ high. For 6 minutes, every 1 second, the change in mass and temperature of the tested sample is recorded (Grześkowiak 2015, Zeinali et al. 2018, Can et al. 2018, Can et al. 2017, Grześkowiak 2017). The assessment of the protective effect is made for the final value of mass loss (360 seconds) based on the following formula:

$$
W=100 \% *\left(1-\frac{E}{A}\right)
$$


where: $W$ is the conventional effectiveness of the impregnate; $E$ is the final mass loss of protected samples [\%]; $A$ is the final mass loss of control samples [\%]

\subsection{Optimization methodology}

Based on the results of control tests, the critical point (the time at which the average sample temperature reached its maximum value) was calculated (Grześkowiak and Moliński 2019). The effectiveness of the protection at the critical point was determined according to the above formula (1) for test variants, assuming the mass loss values $E$ and $A$ at the critical point. Efficiencies were calculated for all time parameters to determine the optimal test time. A formula was proposed for the duration of tests for protected samples with fire retardant preparations, taking as a reference the maximum temperature of the control series:

$$
t=t_{\mathrm{PK}}+t_{\mathrm{PK}} 50 \%
$$

where: $t_{B}$ is the test duration; $t_{P K}$ is the time of the critical point for control tests

\section{Results}

When the control samples were tested, the maximum exhaust gas temperature at the outlet of the pipe was reached within 120 seconds. The temperature value at that time was $410^{\circ} \mathrm{C}$. For comparison, the maximum temperatures of exhaust gases of the tested samples were respectively: $\mathrm{A}-86.68{ }^{\circ} \mathrm{C}$ in $344 \mathrm{~s}$; $\mathrm{B}-130.09^{\circ} \mathrm{C}$ in $34 \mathrm{~s}$; and $\mathrm{C}-131.66^{\circ} \mathrm{C}$ in $338 \mathrm{~s}$. In the case of preparation $B$ there was rapid ignition, reaching the maximum temperature in a short time, after which the temperature decreased significantly to approximately $95{ }^{\circ} \mathrm{C}$. The temperature of exhaust gases for the remaining variants showed an upward trend until the end of the test. The calculated effectiveness, based on mass losses for final values and the critical point, are summarized in Table 1.

Table 1. Effectiveness of fire retardants at $360 \mathrm{~s}$ and at the critical point

\begin{tabular}{lcc}
\hline Variant & $\begin{array}{c}\text { Effectiveness } \\
\text { for final values [\%] }\end{array}$ & $\begin{array}{c}\text { Effectiveness } \\
\text { at critical point [\%] }\end{array}$ \\
\hline $\mathrm{A}$ & 87.99 & 89.61 \\
$\mathrm{~B}$ & 85.95 & 87.29 \\
$\mathrm{C}$ & 75.20 & 88.59 \\
\hline
\end{tabular}


As the results in Table 1 show, the differences in the efficacy values at the critical point and at the end of the test are quite significant, especially for variant $\mathrm{C}$. These differences were respectively $1.62 \%$ for variant A, $1.33 \%$ for B and $13.39 \%$ for $\mathrm{C}$. These changes in efficacy resulted in a need to prolong the time after reaching the critical point so that the differences in efficiencies were not greater than $10 \%$ relative to the efficacy at the endpoint. This situation was observed only in the case of preparation C.

When analyzing the mass loss curves obtained during the test, attention should be paid to the moment of rapid increase in mass loss of the test and control samples (Fig. 1). It is strongly correlated with the moment of ignition of the sample and with a sharp increase in exhaust gas temperature (Fig. 2). Based on the moment of ignition of the sample, as well as the rate of mass loss and temperature, conclusions can be drawn concerning the effectiveness of the given preparation or protection.

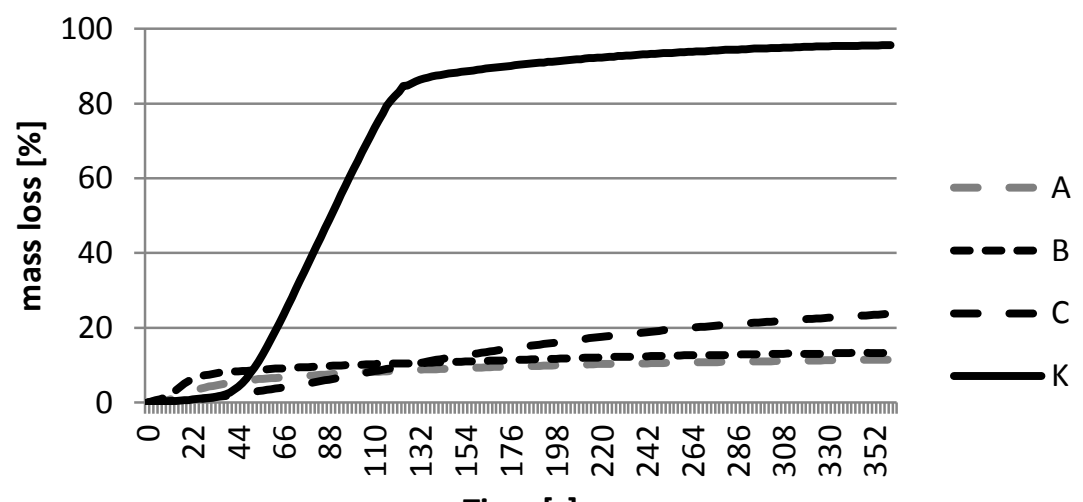

Time [s]

Figure 1. Mass loss curves for the tested and control samples

The time at which the critical point was reached for the control samples was $33.33 \%$ of the originally assumed test time (360 s). Analyzing the differences in the efficacy values obtained for formulation $\mathrm{C}$ between the critical and final point of the test, it was found that the target difference of $10 \%$ was obtained after 162 seconds of measurement. From that moment the difference gradually decreased. This moment occurs at $45 \%$ of the assumed test time. For the remaining test variants, the difference in effectiveness was less than $10 \%$ in the time interval from the critical to the final point. It should be noted that in all of the 
cases studied, the effectiveness of the preparations at both the critical and final point was high despite the relatively low concentration.

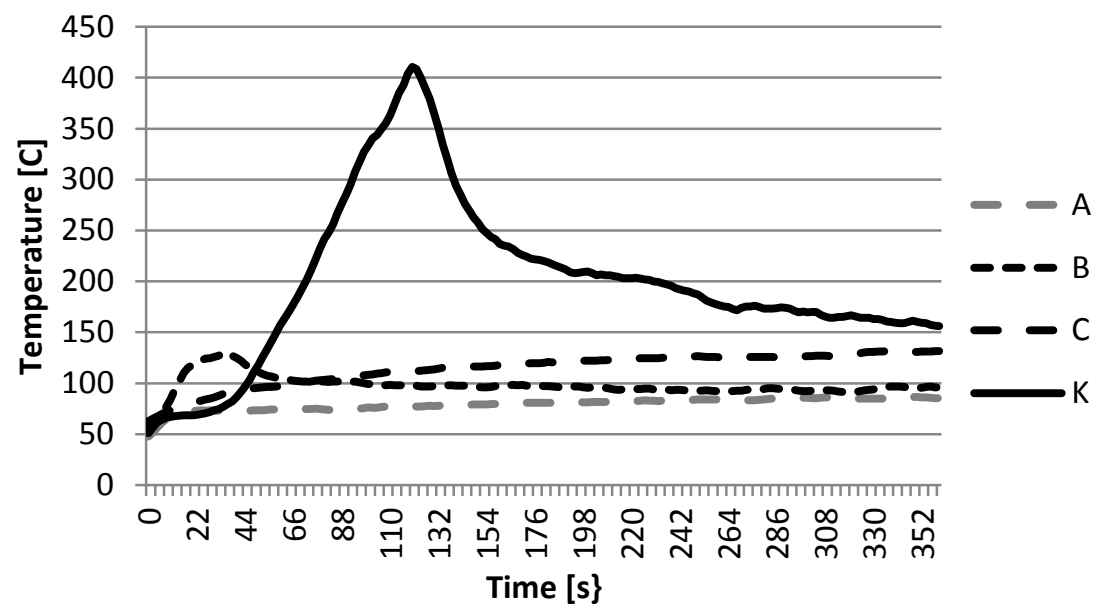

Figure 2. Changes in temperature for tested and control samples

Based on the above results and observations, it was proposed to shorten the testing time to $180 \mathrm{~s}$, which is $50 \%$ of the original time. Ending the test at this time does not significantly affect the ability to accurately determine the effectiveness of protection.

Comparing the MFT method used here with the original ASTM E69-2 method, it should be noted that in the MFT method the samples are exposed to much more severe conditions than in the ASTM method. In the primary method, the flame acts on the sample only for a specified time (4 min) and the temperature values for all samples after this time decrease despite the ignition of the samples. Previous studies (unpublished) carried out by this method showed that the average duration of the test was about 420 seconds, and the mass losses of the control samples and those treated with preparations A and B with the same concentrations were respectively $79.85 \%$ for the control, $10 \%$ for $\mathrm{A}$ and $7.5 \%$ for $\mathrm{B}$, giving efficacies of $87 \%$ and $91 \%$ for preparations A and B respectively.

In the analyzed example, $t_{B}$ is 180 seconds, and the efficiencies calculated for this value are $89.21 \%$ for $\mathrm{A}, 87.37 \%$ for B and $83.65 \%$ for C. 


\section{Conclusions}

1. The experiments have shown that it is possible to shorten the time of testing of the effectiveness of flame retardants and fire properties of wood and wood-based materials, based on the time required to attain the maximum temperature for control samples.

2. MFT tests make it possible to reduce the size and quantity of samples, both of wood and wood-based materials and of fireproof preparations. This is important when controlling the quality of the protection, especially for built-in components.

3. This method can be used to assess the quality of various preparations and the quality of the protection given. By analyzing different types of materials and preparations in comparison with the control, selection of the optimal preparation and the appropriate protection method will be facilitated.

\section{REFERENCES}

ASTM E69-02 (2002): Standard Test Method for Combustible Properties of Treated Wood by the Fire-Tube Apparatus, ASTM International, West Conshohocken, PA. www.astm.org

Can A., Grześkowiak W., Özlüsoylu İ. (2018): Improving the Fire Resistance of Heat Treated Wood by Using Environment-Friendly Substance. Journal of Bartin Faculty of Forestry, 20(3): 519-524.

Can A., Özlüsoylu İ., Grześkowiak W., Sözen E. (2017): Improvement of Fire Performance of Impregnated Wood with Copper Based Chemicals. Proceedings of the 28th International Conference on Wood Science and Technology 2017, Implementation of Wood Science in Woodworking Sector, Zagreb 7-8 December 2017: 21-27.

Chapple S., Anandjiwala R. (2010): Flammability of Natural Fiber-reinforced Composites and Strategies for Fire Retardancy: A Review. Journal of Thermoplastic Composite Materials, published online 5 January 2010. DOI: 10.1177/0892705709356338

Chung W.-T, Lei M.-Y., Tsai K.-C. (2014): Evaluating current fire test methods for determining flammability performance of ceiling materials. Journal of Marine Science and Technology (Taiwan) 22: 196-203. 10.6119/JMST-013-0311-1.

Fanfarová A., Osvaldová L., Gašpercová S. (2016): Testing of Fire Retardants. Applied Mechanics and Materials. 861. 72-79. 10.4028/www.scientific.net/AMM.861.72.

Fouladi M., Namasivayam S.N., Chong C.H., Xin P.Z., Xin S.Y.P., Ghassem M., Najafabadi H.S. (2015): Enhancement of coir fiber fire retardant property. Journal of Engineering Science and Technology, Special Issue on SOMCHE 2014 \& RSCE 2014 Conference, January 2015: 61-72. 
Goldstein I.S. (1973): Degradation and Protection of Wood from Thermal Attack. In: Wood Deterioration and its Prevention by Preservative treatment Vol. 1, Degradation and Protection of Wood, D.P. Nicholas ed. Syracuse Univ. Press, Syracuse N.Y.

Grześkowiak W.Ł. (2015): Guanidine carbonate - component supporting fire retardance in new preservatives for wood and wood-based materials. MC Meeting, WG meeting, Bio-based Building Products and Fire Safe Design of Buildings - Recent Developments. Book of abstracts, Barcelona, Spain 20-21 April 2015: 51-54.

Grześkowiak W.Ł. (2017): Effectiveness of new wood fire retardants using a cone calorimeter. Journal of Fire Sciences 35(6): 565-576. DOI: 10.1177/ 0734904117737464

Grześkowiak W.Ł., Cofta G., Wiśniewski T. (2011): Działanie promieniowania cieplnego na materiały drewnopochodne stosowane $\mathrm{w}$ budownictwie zabezpieczone preparatami ogniochronnymi [Action of thermal radiation on wood-based materials used in buildings protected with fire retardants]. Polskie Stowarzyszenie Mykologów Budownictwa - Seria: Monografie nr 7, Tom XI, Wrocław: 27-32

Grześkowiak W.Ł., Moliński K. (2019): Effect of heating of the protected wood and the time of storage of the preparation on fire protection effectiveness. 49 Międzynarodowe Colloquium Biometryczne, Siedlce 8 - 12 września: 24-26.

Le Van S.L. (1989): Thermal degradation. In: Schniewind, Arnold ed., Concise Encyclopedia of Wood and Wood Based Materials, 1st edition, Elmsford, N.Y., Pergamon Press 1989: 271-273.

Lowden L.A., Hull T.R. (2013) Flammability behaviour of wood and a review of the methods for its reduction. Fire Science Reviews, 2:4.

Marney D.C.O., Russell L.J., Humphrey D.G. (2005): Fire Retardants for Timber Applications - a Literature Review Building Confidence in Timber: APEC Fire Safe Use of Timber in Construction Seminar May 24-26, 2005 Wellington, N.Z.

Oberley W.J. (1991): Fire retardants and products produced therewith related application. World Intellectual Property Organization 1991, WO 91/00327.

Park H.-J., Wen M., Cheon S.-H., Hwang J.-W., Oh S.-W. (2012): Flame retardant performance of wood treated with flame retardant chemicals. J. Korean Wood Sci \& Tech. 40(5): 311-318.

Sulaiha A., Datin Ir. Dr. Siti Aslina H., Mohd Zahirasri M.T. (2019): Fire Test and Effects of Fire Retardant on the Natural Ability of Timber: A Review. Pertanika Journal of Science and Technology 27 (2): 867-895.

White R.H., Dietenberger M.A. (2001): Wood products: thermal degradation and fire. In: Encyclopedia of Materials: Science and Technology, Editors-in-Chief: K.H. Jürgen Buschow, Robert W. Cahn, Merton C. Flemings, Bernard Ilschner, Edward J. Kramer, Subhash Mahajan, and Patrick Veyssière, Elsevier Science Ltd., pp. 9712-9716.

Winandy J.E., Le Van S.L., Schaffer E.L., Lee P.W. (1988): Effect of fire-retardant treatment and redrying on the mechanical properties of Douglas-Fir and Aspen plywood. Res. Pap. FPL-RP-485. Madison, WI: U.S. Departament of Agriculture, Forest Service, Forest Products Laboratory.

Zeinali D., Koalitis D., Schmid J. (2018): Guide for Obtaining Data from Reaction to Fire Tests, ETH Zürich, Switzerland, 2018. DOI 10.3929/ethz-b-000319575 http://www.costfp1404.ethz.ch/publications. 